\title{
How to Ensure Adequate Iron Absorption from Iron-fortified Food
}

\section{Journal Article}

Author(s):

Hurrell, Richard

Publication date:

2002

Permanent link:

https://doi.org/10.3929/ethz-b-000422926

Rights / license:

In Copyright - Non-Commercial Use Permitted

Originally published in:

Nutrition reviews 60, https://doi.org/10.1301/002966402320285137 


\title{
How to Ensure Adequate Iron Absorption from Iron-fortified Food
}

\author{
Richard Hurrell, Ph.D.
}

Iron absorption from an iron-fortified food can be considered adequate if the target population is able to maintain or improve iron status while consuming the fortified food as part of a normal diet. This is not always easy to achieve. In fact, iron is the most difficult mineral to add to foods and it is additionally difficult to ensure adequate absorption. This is because the most soluble and absorbable iron compounds often cause unacceptable color and flavor changes when added to foods. Although less water-soluble iron compounds typically cause no organoleptic problems, they are poorly absorbed because they do not dissolve completely in the gastrointestinal tract during digestion. A further problem is the presence of absorption inhibitors, such as phytic acid or phenolic compounds, in the food vehicle.

This scenario must be considered when designing and developing an iron-fortified food with adequate absorption. The development should proceed systematically in three distinct steps. Firstly, it is necessary to optimize the iron compound with respect to bioavailability and potentially unacceptable sensory changes in the food vehicle. Secondly, the amount of iron absorbed from the fortified food should be adjusted to meet the needs of the consumer. Lastly, efficacy studies should be conducted to demonstrate that regular consumption of the fortified food has a beneficial effect on the iron status of the target population.

\section{Optimization of the Iron Compound}

The iron compound used to fortify a specific food should be the compound with the highest relative bioavailability (RBV) that causes no adverse sensory changes. The food manufacturer can select potential iron compounds based on published data of RBV and their potential to cause color and flavor problems. Such information is given in Table 1 Cost is also an important issue; relative cost values are also given in Table 1. This variable, however,

Dr. Hurrell is with the Laboratory of Human Nutrition, Institute of Food Science ETHZ, PO Box 474, $\mathrm{CH}-8803$ Rüschlikon, Switzerland. changes with the quantity purchased and can be different depending on region of the world.

When potential iron compounds have been selected, they should be added to the food vehicle and sensory changes should be monitored during processing, storage, and meal preparation. Sensory panels should be trained to evaluate changes in flavor, aroma, and color, and if necessary, parameters such as texture and sedimentation. A useful method to test for potential fat oxidation during storage of iron-fortified cereal flours is pentane formation. ${ }^{1}$

When selecting the iron compound for the sensory studies, the food technologist can choose from three groups of conventional compounds, which differ in their solubility in water or dilute acid (Table 1), or from a small group of novel compounds. These compounds are described in the following sections.

\section{Conventional Iron Compounds}

Freely water-soluble compounds. These compounds

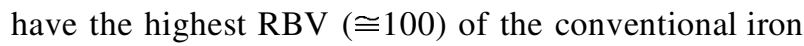
compounds and, when acceptable organoleptically, they should be the first choice for food fortification. In practice, ferrous sulfate is the only water-soluble compound that is commonly added to foods. Because it readily causes sensory changes, however, it can only be added satisfactorily to a small number of food vehicles. Other water-soluble compounds have a similar RBV to ferrous sulfate, but provoke similar sensory changes and are more expensive.

Ferrous sulfate is used to fortify infant formula, bread, and pasta. ${ }^{2}$ It can also be added to wheat flour when stored for short periods ${ }^{3}$ but may provoke fat oxidation and off flavors in wheat and other cereal flours stored for longer periods. ${ }^{1,4}$ It is possible that the purity of ferrous sulfate plays an important role. Fat oxidation can also be a problem with iron fortification of liquid milk. ${ }^{5}$ In this vehicle, ferric ammonium citrate has been reported to perform better than ferrous sulfate. ${ }^{6,7}$ Ferrous sulfate and other soluble iron compounds have been reported to cause unacceptable color changes in cocoa products,${ }^{8}$ infant cereals, ${ }^{4}$ salt,${ }^{9}$ and tortillas. Soluble iron compounds may cause a metallic taste in bouillon cubes 


\begin{tabular}{|c|c|c|c|c|c|c|}
\hline \multirow[b]{2}{*}{ Iron Compound } & \multirow[b]{2}{*}{$\begin{array}{l}\text { Approximate } \\
\text { Fe }(\%)\end{array}$} & \multicolumn{2}{|c|}{$\begin{array}{c}\text { Average Relative } \\
\text { Bioavailability } \\
\end{array}$} & \multicolumn{2}{|c|}{$\begin{array}{l}\text { Potential for Adverse } \\
\text { Organoleptic Changes }\end{array}$} & \multirow{2}{*}{$\begin{array}{c}\text { Approximate } \\
\text { Relative } \\
\text { Cost* }\end{array}$} \\
\hline & & $\frac{\text { b10a }}{\text { Rat }}$ & $\frac{a b m i n}{\text { Man }}$ & Color & $\begin{array}{c}\text { Fat } \\
\text { Oxidation }\end{array}$ & \\
\hline \multicolumn{7}{|l|}{ Freely water soluble } \\
\hline Ferrous sulfate $7 \mathrm{H}_{2} \mathrm{O}$ & 20 & 100 & 100 & \multirow{7}{*}{ high } & \multirow{7}{*}{ high } & 1.0 \\
\hline Dried ferrous sulfate & 33 & 100 & 100 & & & 0.7 \\
\hline Ferrous gluconate & 12 & 97 & 89 & & & 5.1 \\
\hline Ferrous lactate & 19 & - & 106 & & & 4.1 \\
\hline Ferric ammonium citrate & 18 & 107 & - & & & 2.1 \\
\hline Ferrous ammonium sulfate & 14 & 99 & - & & & 2.1 \\
\hline Ferric choline citrate & 14 & 102 & - & & & 11.0 \\
\hline \multicolumn{7}{|l|}{$\begin{array}{l}\text { Poorly water soluble/soluble } \\
\text { in dilute acid }\end{array}$} \\
\hline Ferrous fumarate & 33 & 95 & 100 & \multirow{6}{*}{ low } & \multirow{6}{*}{ low } & 1.3 \\
\hline Ferrous succinate & 35 & 119 & 92 & & & 4.1 \\
\hline Ferric saccharate & 10 & 92 & 74 & & & 5.2 \\
\hline Ferric glycerophosphate & 15 & 93 & - & & & 10.5 \\
\hline Ferrous citrate & 24 & 76 & 74 & & & 3.9 \\
\hline Ferrous tartrate & 22 & 77 & 62 & & & 3.9 \\
\hline \multicolumn{7}{|l|}{$\begin{array}{l}\text { Water insoluble/poorly soluble } \\
\text { in dilute acid }\end{array}$} \\
\hline Ferric pyrophosphate & 25 & $45-58$ & $21-74$ & \multirow{7}{*}{ negligible } & \multirow{7}{*}{ negligible } & 2.3 \\
\hline Ferric orthophosphate & 28 & $6-46$ & $25-32$ & & & 4.1 \\
\hline \multicolumn{7}{|l|}{ Elemental Fe powders: } \\
\hline electrolytic & 97 & $16-70$ & 75 & & & $-^{+}$ \\
\hline H-reduced & 97 & $13-54$ & $13-148$ & & & $-^{+}$ \\
\hline Co-reduced & 97 & $12-32$ & ND & & & $-^{+}$ \\
\hline atomized & 97 & ND & ND & & & $-^{+}$ \\
\hline carbonyl & 99 & $35-66$ & $5-20$ & & & $-^{+}$ \\
\hline
\end{tabular}

* Relative to ferrous sulfate $7 \mathrm{H}_{2} \mathrm{O}=1.0$, for the same level of total iron.

${ }^{+}$In general less expensive than ferrous sulfate. Cost of different powder types varies approximately sevenfold, with carbonyl iron being the most expensive.

$\mathrm{ND}=$ not determined.

Source: adapted from Hurrell, reference 2.

and fruit drinks, and may cause precipitates to form in soy sauce, fish sauce, and tea infusions.

Compounds poorly soluble in water but soluble in dilute acid. When a freely soluble iron compound causes unacceptable sensory changes to food vehicles, the next step is to evaluate compounds that are water-soluble but are still readily soluble in dilute acid. These compounds (Table 1) cause less organoleptic changes than the watersoluble compounds but have a similar or slightly lower RBV depending on how well they dissolve in the gastric juice during digestion. Ferrous fumarate and ferrous succinate are the preferred compounds in this group because adult humans can absorb them as well as ferrous sulfate. Ferric saccharate is a useful alternative. The bioavailabilities of ferrous citrate, ferrous tartrate, and ferric glycerophosphate are also moderately good and these compounds should be considered for food fortification. Presently only ferrous fumarate and ferric sac- charate are widely used as iron fortificants. Ferrous fumarate is added to commercial infant cereals and ferric saccharate is added to chocolate drink powders.

Water-insoluble compounds, also poorly soluble in dilute acid. These compounds are the least well absorbed of the iron fortificants and as such are the last choice for food fortification. Some compounds from this group can be useful fortificants, whereas it may never be able to ensure adequate absorption with others. Their main characteristic is that they dissolve slowly and incompletely in the gastric juice during digestion. Their absorption is difficult to predict because the extent to which they dissolve depends on their physical characteristics (size, shape, and surface area of particles) and the composition of the meal. Physical characteristics can vary widely. There are two different types of insoluble iron fortificants: the iron phosphate compounds and the elemental iron powders. 
Phosphate compounds include ferric pyrophosphate and ferric orthophosphate. Ferric pyrophosphate, in particular, has been widely used by European companies to fortify infant cereals and chocolate drink powders. In human studies, labeled ferric pyrophosphate has been reported to be 25 to $75 \%$ as well absorbed as ferrous sulfate, ${ }^{1,10}$ as opposed to 25 to $32 \%$ for ferric orthophosphate. ${ }^{11,12}$ In a recent infant study with stable isotopes, iron absorption from a soy-based cereal fortified with ferric pyrophosphate was approximately one-third of the absorption from the same cereal fortified with ferrous fumarate $(1.3 \%$ versus $4.1 \%) .{ }^{13}$ Despite the relatively low absorption of ferric pyrophosphate, efficacy studies indicate that it could be a useful iron fortificant. Pakistani infants from a lower socioeconomic class were fed a wheat-milk complementary food fortified with ferric pyrophosphate or ferrous fumarate $(7.5 \mathrm{mg} \mathrm{Fe} / 100 \mathrm{~g})$ from 4 to 12 months of age as part of their normal diet. ${ }^{14}$ After 12 months the iron status of the infants fed ferric pyrophosphate was not different from those receiving ferrous fumarate, but iron status was significantly higher than the control group receiving no iron $(\mathrm{Hb} 10.4$ versus $9.9 \mathrm{~g} / \mathrm{dL}$ $[P<0.05]$, serum ferritin 13.3 versus $8.8 \mu \mathrm{g} / \mathrm{L}[P<$ $0.05])$. This study is difficult to interpret, however, because approximately $50 \%$ of the infants were iron deficient (serum ferritin $<10 \mu \mathrm{g} / \mathrm{dL}$ ) at 12 months, indicating that the level of fortification iron ( $3 \mathrm{mg} /$ day) was too low for the target population, and that a higher level could have had a greater impact on iron status.

An important consideration with ferric pyrophosphate and ferric orthophosphate is that bioavailability may change during food processing. When ferric pyrophosphate was used to fortify a chocolate drink powder, the RBV to humans decreased from 75 without processing to only 21 after vacuum drying at $100^{\circ} \mathrm{C} .{ }^{10}$ On the other hand, when ferric pyrophosphate and ferric orthophosphate were used to fortify liquid soy or milkbased infant formulas, RBV in rats increased from 39 to 93 and from 78 to 125 , respectively after sterilization. ${ }^{15,16}$

Choosing an elemental iron powder for food fortification is very difficult and, although iron powders are widely used to fortify cereal flours, breakfast cereals, and infant cereals, ensuring adequate absorption needs careful consideration. There are five different types of elemental iron powders used for food fortification. Each powder type is produced by a different manufacturing process and has a distinct particle size distribution, density, surface area, chemistry, and shape, all of which influence dissolution of the powder in the gastric juice and therefore its bioavailability. Different batches of the same powder type may have different dissolution characteristics. The powder types are electrolytic, hydrogen
(H)-reduced, carbon monoxide (CO)-reduced, atomized (reduced), and carbonyl.

The usefulness of elemental iron powders for food fortification was recently addressed by an expert panel. ${ }^{17}$ The panel concluded that electrolytic iron powder was the only iron powder that had been demonstrated as a useful iron fortificant, and they singled out Glidden 131 (OMG, Americas, USA) to be the iron powder of choice for food fortification at the present time. This conclusion was based on results from three types of study. Firstly is was based on an efficacy study in infants who demonstrated improved iron status when fed electrolytic ironfortified infant cereal. ${ }^{18}$ Secondly is was based on results from a human bioavailability study with radiolabeled electrolytic iron, a powder that had similar (but not identical) physical characteristics to the commercial powder, and that gave an absorption $75 \%$ of that of ferrous sulfate. ${ }^{12}$ Finally, further support for its modest bioavailability came from five independent rat hemoglobin repletion studies with Glidden 131 which reported RBV values from 42 to 59 , mean $48 .{ }^{17}$ Other electrolytic iron powders have given RBV values from 16 to 70 (Table 1). At the present time, electrolytic iron is used widely to fortify infant cereals in the United States.

Based on the current evidence, it was not possible for the panel to decide whether or not H-reduced, COreduced, atomized, or carbonyl iron powders could be useful iron fortificants. ${ }^{17}$ No good human efficacy data is available with any of these powders. Rat studies on commercial iron powders made between 1971 and 1991 indicated that carbonyl iron was as well absorbed as electrolytic iron, H-reduced iron was less well absorbed than electrolytic iron, and CO-reduced iron was poorly absorbed. Reduced iron powders with large particle size $(100$ mesh $>149 \mu \mathrm{m})$ had the lowest bioavailability in rat studies. The panel recommended that these low-cost, large-particle size powders should not be used for food fortification.

Although isotopically labeled H-reduced iron has been examined several times in human bioavailability studies, the experimentally labeled compounds were so different from the commercial iron powders that the results could not be used to judge the usefulness of the commercial powders. Isotopically labeled commercial carbonyl iron, however, gave RBV values of only 5 to 20 in human subjects consuming a variety of meals. ${ }^{19} \mathrm{Cou}-$ pled with its higher cost, this makes carbonyl iron a less attractive option for food fortification. There are no published rat or human studies on which to evaluate the usefulness of atomized iron.

\section{Novel Iron Compounds}

Sodium iron ethylenediaminetetraacetec acid (NaFeEDTA). The major advantage of NaFeEDTA over other fortification compounds is that it prevents iron 
binding to inhibitors of iron absorption, and to phytic acid in particular. Thus iron absorption from NaFeEDTA, which is added to cereal foods or to meals containing a considerable amount of phytic acid, is two- to threefold higher than from ferrous sulfate. ${ }^{20}$ When dietary inhibitors are at a lower level, the absorption of NaFeEDTA may be similar to the absorption of ferrous sulfate. ${ }^{21} \mathrm{NaFeEDTA}$ is slowly water-soluble and thus may cause unacceptable color changes in some food vehicles, although it does not provoke fat oxidation in stored wheat flour. ${ }^{22}$ Efficacy studies have demonstrated improved iron status in populations consuming NaFeEDTA-fortifed fish sauce, ${ }^{23,24}$ sugar, ${ }^{25}$ and curry powder. ${ }^{26}$ It is approximately six times more expensive than ferrous sulfate and has recently been approved by the Joint FAO/WHO Expert Committee on Food Additives. ${ }^{27}$ It is a useful compound for the fortification of cereal foods, fish sauce, and soy sauce.

Ferrous bisglycinate. This compound has been developed commercially by Albion Laboratories, USA, and because its manufacturing process and exact composition are a closely guarded secret, it has not been possible to get a completely independent evaluation of its usefulness for food fortification. Makers of the product claim it protects iron from dietary inhibitors and recent studies have reported a fourfold higher iron absorption by humans from a whole-maize meal fortified with ferrous bisglycinate than from a meal fortified with ferrous sulfate. ${ }^{28}$ An earlier study, however, does not support this report because infants fed a whole-grain infant cereal absorbed iron to a similar extent from ferrous bisglycinate and from ferrous sulfate. ${ }^{29}$ Its high cost, its tendency to cause unwanted color reactions, and its tendency to provoke fat oxidation in stored cereal flours, make it an unsuitable fortification compound for many food vehicles. It does, however, appear to be a useful fortication compound for liquid milk ${ }^{30}$ and perhaps other milkbased products.

Hemoglobin. When used as an iron fortificant, hemoglobin has been added to food in the form of dried bovine red blood cells. Its main advantage is that absorption is relatively high and predictable. This is because heme iron is absorbed still bound within the porphyrin ring of the heme molecule and is naturally protected from the main inhibitors of iron absorption. Monsen et al. ${ }^{31}$ estimated that $15-35 \%$ of heme iron would be absorbed in adults depending on iron stores, and heme iron absorption by infants was reported to be $14 \%$ from an infant cereal fortified with hemoglobin. ${ }^{32}$ This is approximately double what has been reported from a ferrous sulfate-fortified infant cereal. ${ }^{33}$ In Latin America, where the supply of animal blood is plentiful in some countries, hemoglobin-fortified foods have been demonstrated to improve the iron status of infants and young children. ${ }^{34,35}$ Nevertheless, its low iron content (0.34\%), intense red color, and the technical difficulties involved in its collection, drying, and storage make it an unattractive iron compound for many applications.

Encapsulated iron compounds. Encapsulated ferrous sulfate and encapsulated ferrous fumarate are both available commercially. The coating prevents or retards many of the adverse sensory changes that are associated with these compounds. The coating material is commonly hydrogenated oils, maltodextrin, or ethyl cellulose and has been reported to have little influence on the relative bioavailability of these compounds in rat assays. ${ }^{36}$ Encapsulated iron compounds have proven useful in dried infant formula and dried infant cereals. More recently they have been used in developing countries to fortify salt where the high moisture content and impurities make addition of iron compounds difficult. Encapsulated iron compounds may similarly prove useful to fortify cereal flours; however, there is little evidence yet to support this possibility. One potential problem with some food vehicles is the heat instability of the capsules. Before including encapsulated compounds in fortification programs, human bioavailability or efficacy studies should be conducted to demonstrate that the capsule is removed during digestion, and that the iron is adequately absorbed.

\section{Adjusting Iron Absorption}

Once the iron compound has been selected, the second step in the development of an iron-fortified food is to adjust the amount of iron absorbed from that food to a level that meets the needs of the consumer. For this step, it is necessary to know the mean iron intake ( $\mathrm{mg}$ /day) of the target population, the expected dietary iron absorption from the fortified food, and the consumption pattern of the food vehicle. For most populations, the requirements of absorbable iron are approximately $1-1.5 \mathrm{mg} /$ day. The amount of fortification iron added to the food vehicle then depends on the mean daily iron intake from the normal diet and its expected absorption, and should be calculated so as to achieve a total daily intake of absorbable iron that will ensure adequate iron status.

Whereas absorption of iron from the fortified food can be estimated, a safer approach to ensuring the success of a fortification program is to measure iron absorption from the fortified food in the target population. This can be done using radioisotopes ${ }^{1,28,37}$ or stable isotopes. ${ }^{13,29,38}$ If the iron compound to be tested dissolves slowly or incompletely in the gastric juice, it must be intrinsically labeled with isotope before testing. It is not possible to measure iron absorption from elemental iron powders or iron phosphates using the extrinsic tag technique. This is because these compounds dissolve slowly and incompletely in the gastric juice and will be less well absorbed than the extrinsic tag. It is also uncertain 
whether the extrinsic tag technique will give reliable absorption values for a compound like ferrous fumarate, which dissolves more slowly in the gastric juice than the extrinsic tag. Ideally all compounds to be tested should be labeled intrinsically and they should be synthesized in collaboration with the manufacturer of the equivalent commercial iron compound. In this way, the manufacturer can confirm that the intrinsically labeled compound is equivalent to the commercial compound. Synthesizing isotopically labeled elemental iron powders or labeled encapsulated iron, both of which are identical in all other respects to the equivalent commercial compound, is extremely difficult. An alternative approach to produce radiolabeled compounds is to irradiate the commercial elemental iron powders. ${ }^{19}$

Once the expected level of absorption is known, the amount of fortification iron added to the food can be determined. With the more insoluble iron compounds, such as elemental iron powders or iron phosphates, it might be necessary to add two to three times more iron than for ferrous sulfate of ferrous fumarate. In addition, with food vehicles that contain iron absorption inhibitors, or that are consumed with high-phytate diets, it might be necessary to add an absorption enhancer in order to ensure adequate absorption. Ascorbic acid is the most commonly used iron absorption enhancer. An alternative might be sodium EDTA. ${ }^{37}$ Other possibilities are sodium hexametaphosphate, sodium acid sulfate, ${ }^{39}$ and perhaps succinic acid. ${ }^{40}$ With cereal-based complementary foods, phytic acid removal is a useful approach to improving the absorption of fortification iron.

\section{Ascorbic Acid Addition}

Ascorbic acid can increase the absorption of fortification iron considerably. Ascorbic acid reportedly increases human absorption of ferrous sulfate, ferric chloride, ferric ammonium citrate, ferrous fumarate, ferric orthophosphate, and electrolytic iron from cereal meals, infant formulas, and chocolate drinks. The enhancing effect is related to its reducing power and chelating action, and the magnitude of the effect depends on the amount of ascorbic acid added, the level of iron fortification, and the amount of inhibitors (phytate and polyphenols) present in the meal. Several studies have shown that progressively increasing the ascorbic acid content in an iron-fortified food progressively increases fractional iron absorption. ${ }^{41-44}$ The question for the manufacturer is how much ascorbic acid must be added to achieve a meaningful increase in iron absorption.

Although this is difficult to estimate with precision, several studies have reported useful increases in iron absorption with a ratio of ascorbic acid to iron by weight of approximately 6:1 (2:1 molar ratio). It should be stressed, however, that this might not be sufficient for meals high in phytate or phenolic compounds. An ascor- bic acid-to-iron ratio (weight:weight) of approximately 6:1 has been reported to increase iron absorption by 2 - to 12 -fold in adult women fed infant formula, infant cereal, and enriched maize porridge fortified with ferrous sulfate or ferric ammonium citrate acid; ${ }^{45}$ iron absorption is increased by threefold from a ferrous sulfate-fortified chocolate drink fed to children; ${ }^{43}$ iron absorption is increased by 2.5 -fold from a ferric chloride-fortified liquid formula meal fed to adults, ${ }^{41}$ and iron absorption is increased approximately twofold from ferrous sulfatefortified infant formula fed to infants. ${ }^{46}$ However, an ascorbic acid-to-iron ratio (weight:weight) of 10:1 was necessary to approximately double iron absorption by adults from maize porridge ${ }^{44}$ and high-phytate bread ${ }^{42}$ (both were fortified with ferrous sulfate). In a study with insoluble fortification iron, Forbes et al. ${ }^{12}$ reported that adding $100 \mathrm{mg}$ ascorbic acid to a farina meal containing $6 \mathrm{mg} \mathrm{Fe}$ (16:1 weight ratio) as ferric orthophosphate, electrolytic iron, or ferrous sulfate, increased iron absorption by 4-, 2.4-, and 3-fold, respectively. However, using an ascorbic acid-to-iron weight ratio of 4:1 did not improve absorption of hydrogen-reduced iron from breakfast cereal. ${ }^{47}$

Although one can assume ascorbic acid will increase the absorption of all fortification iron compounds, some uncertainty still exists concerning the influence of ascorbic acid on ferrous fumarate absorption. Iron absorption by adults from ferrous fumarate added to a chocolate drink was reportedly unchanged upon addition of ascorbic acid at a 5:1 weight ratio. ${ }^{10}$ In the same study, iron absorption from ferrous fumarate added to a liquid formula meal was increased only 1.6-fold upon addition of ascorbic acid at a 14:1 weight ratio. More recently, Davidsson et al. ${ }^{13}$ were unable to demonstrate a significant increase in iron absorption by infants from a ferrous fumarate-fortified wheat-soy cereal when the ascorbic acid-to-iron weight ratio was increased from 10:1 to 20:1. By contrast, increasing the ascorbic acid-to-iron weight ratio from approximately 7.1 to 13.1 significantly increased iron absorption by infants consuming ferrous sulfate-fortified soy formula (from $5.9 \%$ to $9.6 \%$ ), ${ }^{48}$ as well as by adults consuming a ferrous sulfate-fortified pea protein formula. ${ }^{49}$ Similarly increasing the iron-toascorbic acid weight ratio from approximately $2: 1$ to $5: 1$ in a ferrous sulfate-fortified school breakfast meal of wheat bread and a milk-soy cereal drink significantly increased iron absorption by Peruvian school children from $5.1 \%$ to $8.2 \% .^{50}$

The main problem with ascorbic acid, however, is its susceptibility to losses during storage and food preparation. Storage losses can be unacceptably high under hot and humid conditions and although sophisticated packages can largely prevent degradation, they may be too expensive for many applications. It has not been possible 
to use ascorbic acid as an enhancer of iron absorption in wheat flour or salt.

\section{Sodium EDTA}

An alternative enhancer to ascorbic acid is sodium EDTA. This compound has the disadvantage of not being an essential nutrient although it is an accepted food additive in many countries. ${ }^{20}$ It has the advantage, however, of being stable during storage and food preparation. Sodium EDTA would be particularly useful if it enhanced the absorption of those water-insoluble compounds that are organoleptically more inert. Until now it has only been demonstrated to enhance the absorption of ferrous sulfate.

Several studies have demonstrated a positive effect of sodium EDTA on iron absorption from ferrous sulfate-fortified foods. El-Guindi et al. ${ }^{51}$ added equimolar quantities of ferrous sulfate and sodium EDTA to Egyptian bread and reported that iron absorption increased from $2.1 \%$ to $5.3 \%$. McPhail et al. ${ }^{52}$ first demonstrated that sodium EDTA might be more effective at EDTAto-iron molar ratios of less than 1 . They added sodium ETDA to a ferrous sulfate-fortified rice meal and reported a threefold increase in absorption at EDTA:Fe molar ratios of $0.25: 1$ and $0.5: 1$; this was compared with a twofold increase at a 1:1 molar ratio. Davidsson et al. ${ }^{50}$ confirmed these findings and reported similar increases $(30-60 \%)$ in iron absorption by Peruvian school children from a ferrous sulfate-fortified breakfast meal when sodium EDTA was added at EDTA:Fe molar ratios of $0.3: 1,0.7: 1$, or $1: 1$. By contrast, Hurrell et al. ${ }^{37}$ reported that a 1:1 molar ratio was most effective at increasing iron absorption from a high-phytate infant cereal, although with a lower-phytate cereal a ratio of $0.7: 1$ increased iron absorption to the same extent as a ratio of $1: 1$. With the exception of high-phytate foods, a molar ratio of EDTA:Fe of approximately $0.5: 1$ can be used to enhance iron absorption from foods fortified with ferrous sulfate and probably other soluble iron compounds. The advantage of adding ferrous sulfate plus sodium EDTA rather than adding NaFeEDTA could relate to sensory effects, cost, or legislation.

Presently it is uncertain whether sodium EDTA will enhance the absorption of less soluble iron compounds. A molar ratio of EDTA:Fe of 0.5:1 did not improve the absorption of an experimental H-reduced iron from breakfast cereal. ${ }^{47}$ Similarly a 1:1 molar ratio did not improve iron absorption from ferrous fumarate-fortified tortillas in adolescent girls ${ }^{38}$ or from ferric pyrophosphate-fortified infant cereals in adults. ${ }^{37}$ In the latter study, ferrous sulfate absorption from infant cereal was increased threefold with a molar EDTA:Fe ratio of 1:1. One explanation could be that ferrous sulfate rapidly dissolves in gastric juice and forms FeEDTA, whereas the less soluble iron compounds dissolve more slowly in the gastric juice permitting EDTA to combine in preference with other food components.

\section{Phytic Acid Removal or Degradation}

Decreasing phytic acid could be a particularly useful strategy to improve iron absorption from cereal- and legume-based complementary foods and from soy-based infant formula. However, phytic acid is a potent inhibitor of iron absorption even at low concentrations and there is some uncertainty regarding the degree to which phytic acid levels must be reduced to achieve a meaningful increase in iron absorption. With ferrous sulfate-fortified soy formulas based on soy isolates, the phytic acid content of the isolates $(0.7-0.8 \%)$ had to be reduced by 85 to $98 \%(0.02-0.1 \%$ phytic acid) to achieve a two- to threefold increase in iron absorption by adults. ${ }^{53}$ When phytic acid was completely degraded $(<0.01 \%)$, iron absorption increased three- to fivefold. In a follow-up study, complete phytic acid degradation in commercial soy formula fed to infants increased iron absorption 2.2-fold compared with only 1.3 -fold with $83 \%$ dephytinization. ${ }^{48}$ Complete phytate degradation in an experimental pea isolate infant formula fed to adults similarly increased iron absorption 1.6-fold. ${ }^{49}$

Studies with ferrous sulfate-fortified cereal foods indicate that iron absorption is progressively increased as the phytic acid level is reduced. Hallberg et al. ${ }^{54}$ added decreasing amounts of free phytic acid to fortified bread rolls. Decreasing the phytic acid content from approximately $1 \%$ to $0.1 \%$ resulted in a twofold increase in iron absorption, whereas a reduction to $0.01 \%$ increased absorption fourfold. Siegenberg et al. ${ }^{42}$ varied the phytic acid content of a fortified bread meal by adding varying quantities of phytate-free and regular maize bran. They reported that reducing phytic acid from $0.25 \%$ to $0.06 \%$ increased iron absorption approximately twofold, but could demonstrate little further improvement in iron absorption at $0.04 \%$ phytate. More recently investigators reported that complete degradation of phytic acid in wheat, maize, oat, and rice infant cereals increased iron absorption up to tenfold. ${ }^{55}$ Clearly it would be best to remove phytic acid completely from infant foods. However, this might not always be achievable and, based on the studies of Hallberg et al., ${ }^{54}$ Siegenberg et al., ${ }^{42}$ and Hurrell et al., ${ }^{53}$ it can be estimated that reducing the phytic acid:iron molar ratio below 1:1 should result in a useful increase in iron absorption.

There are several ways to decrease the phytic acid level in cereal- and legume-based complementary foods. ${ }^{55}$ These methods include milling, water washing of milled flour, ${ }^{56}$ and dialysis and ultra filtration of acidor alkali-treated protein isolates. An alternative approach is the soaking and germination of the cereal and legume grains. ${ }^{57,58}$ These traditional processes activate native phytases that degrade phytic acid by removing the phos- 
phate groups. Fermentation with food grade microorganisms similarly activates native phytases by reducing $\mathrm{pH}$ and by providing additional phytases, particularly from yeast and molds. ${ }^{59}$

The most effective way to completely degrade phytic acid is to add commercial phytase. ${ }^{33,48,49}$ An alternative phytase source, however, might be certain cereal grains themselves. The phytase content of cereal grains and legume seeds varies considerably, with legumes in general having low activity. ${ }^{60}$ Whole wheat and whole rye have the highest phytase activity and researchers have suggested using these sources to degrade phytic acid in complementary foods based on mixtures of other cereals and legumes. ${ }^{60,61}$

\section{Demonstrating a Benefit to Iron Status}

Both efficacy and effectiveness studies have been used to demonstrate a positive effect of iron-fortified foods on iron status; however, to complete the development of an iron-fortified food only the simpler efficacy study is necessary. This can be a relatively small investigation that monitors, with a carefully controlled protocol, the iron status of a group of subjects consuming a known quantity of an iron-fortified food over a period of approximately 6 to 9 months. The efficacy study should demonstrate that subjects in need of dietary iron could use, within their normal dietary regimes, the iron provided by the fortified food. Most efficacy studies have been therapeutic in nature and have tried to demonstrate that iron-deficient subjects improve their iron status. Such a study recently demonstrated that NaFeEDTAfortified fish sauce improved the iron status of Vietnamese women. ${ }^{24}$ Prophylactic studies can also be considered. This design uses the iron-fortified food to maintain iron status. Walter et al. ${ }^{18}$ monitored the efficacy of an electrolytic iron-fortified infant cereal by measuring how well this complementary food maintained an adequate iron status in infants, and Elwood ${ }^{62}$ attempted a similar study design with iron-fortified flour after first repleting anemic women by iron supplementation.

An effectiveness study can be considered later by government ministries before launching into a major fortification program at country or state level. The effectiveness study investigates the "real life" situation and monitors over a period of 1 to 2 years the iron status of at-risk population groups that are part of a relatively large test population for which an iron-fortified food has been made available as part of the normal diet. In the effectiveness study, the ability of the iron-fortified food to improve iron status depends not only on the efficacy of the iron fortification but also on other factors such as cost, taste, availability, choice, health care, changes in income, and social marketing of the product. Effectiveness may well be different in different populations. The investigations by Viteri et al. ${ }^{25}$ in Guatemala on the impact of NaFeEDTA-fortified sugar can be considered an effectiveness study.

One major consideration when designing efficacy or effectiveness studies is the choice of iron status parameters to monitor. Many studies in the past have used hemoglobin only and have failed to demonstrate a clear improvement. Hemoglobin is a poor measure of iron status because it can be decreased by inflammation, malaria, and deficiencies of folic acid, vitamin $B_{12}$, and vitamin $A$, all of which are common in many developing countries. ${ }^{63}$ It is highly recommended that serum transferrin receptor be used to monitor iron status together with serum ferritin, zinc protoporphyrin, and hemoglobin. ${ }^{63}$

1. Hurrell RF, Furniss DE, Burri J, et al. Iron fortification of infant cereals: a proposal for the use of ferrous fumarate or ferrous succinate. Am J Clin Nutr 1989; 49:1274-82

2. Hurrell RF. Iron. In: Hurrell RF, ed. The mineral fortification of foods. Surrey: Leatherhead Food RA, Leatherhead Publishing, 1999:54-93

3. Cook JD, Reusser M. Iron fortification: an update. Am J Clin Nutr 1983;38:648-59

4. Hurrell RF. Bioavailability of different iron compounds to fortify formulas and cereals: technological problems. In: Steckel A, ed. Iron nutrition in infancy and childhood. New York: Raven Press, 1984

5. Cocodrilli G, Shah N. Beverages. In: Clydesdale FM, Wiemer KL, eds. Iron fortification of foods. Orlando: Academic Press, 1985:145-54

6. Edmonson LF, Douglas FW, Avants JK. Enrichment of pasteurized whole milk with iron. J Dairy Sci 1971;54:1422-6

7. Wang CF, King RL. Chemical and sensory evaluation of iron fortified milk. J Food Sci 1973; 38:938-40

8. Douglas FW, Rainey NH, Wong NP, et al. Color, flavor, and iron bioavailability in iron-fortified chololate milk. J Dairy Sci 1981;64:1785-93

9. Rao NBS. Salt. In: Clydesdale FM, Wiemer KL, eds. Iron fortification of foods. Orlando: Academic Press, 1985:155-64

10. Hurrell RF, Reddy MB, Dassenko SA, et al. Ferrous fumarate fortification of a chocolate drink powder. Br J Nutr 1991;65:271-83

11. Cook JD, Minnich V, Moore CV, et al. Absorption of fortification iron in bread. Am J Clin Nutr 1973;26: 861-72

12. Forbes AL, Adams CE, Arnaud MJ, et al. Comparison of in vitro, animal and clinical determinations of iron bioavailability: International Nutritional Anemia Consultative Group Task Force report on iron bioavailability. Am J Clin Nutr 1989;49:225-38

13. Davidsson L, Kastenmayer $\mathrm{P}$, Szajewska $\mathrm{H}$, et al. Iron bioavailability in infants from an infant cereal fortified with ferric pyrophosphate or ferrous fumarate. Am J Clin Nutr 2000;71:1597-602

14. Javaid N, Haschke F, Pietschnig B, et al. Interaction between infections, malnutrition and iron nutritional 
status in Pakistani infants. Acta Paediatr 1991;374: S141-50

15. Theuer RC, Kemmerer KS, Martin WH, et al. Effect of processing on availability of iron salts in liquid infant formula products: experimental soy isolate formulas. J Agric Food Chem 1971;55:555-8

16. Theuer RC, Martin WH, Wallender JF, Sarret HP. Effect of processing on availability of salts in liquid infant formula products: experimental milk-based formulas. J Agric Food Chem 1973;21:482-5

17. Hurrell RF, Bothwell T, Cook JD, et al. The usefulness of elemental iron for cereal flour fortification. Nutr Rev 2002 in press

18. Walter T, Dallman PR, Pizarro F, et al. Effectiveness of iron-fortified cereal in prevention of iron deficiency anaemia. Pediatrics 1993;91:976-82

19. Hallberg L, Brune M, Rossander L. Low availability of carbonyl iron in man: studies on iron fortification of wheat flour. Am J Clin Nutr 1986;43:59-67

20. International Nutritional Anemia Consultative Group (INACG). Iron EDTA for food fortification. Washington, DC: The Nutrition Foundation/ILSI, 1993

21. Fidler MC, Davidsson L, Walczyk T, Hurrell RF. Iron bioavailability from iron fortified fish sauce and soy sauce. Ann Nutr Metab 2001;45(suppl 1):362

22. Hurrell RF. Preventing iron deficiency through food fortification. Nutr Rev 1997;55:210-22

23. Garby L, Areekul S. Iron supplementation in Thai fish sauce. Ann Trop Med Parasitol 1974;68:467-76

24. Thuy PV, Berger J, Davidsson L, et al. Regular consumption of NaFeEDTA fortified fish sauce improves iron status of anemic Vietnamese women. Ann Nutr Metab 2001;45(suppl 1):116

25. Viteri FE, Alvarez E, Batres R, et al. Fortification of sugar with iron sodium ethylenediaminotetracetate (NaFeEDTA) improves iron status in semirural Guatemalan populations. Am J Clin Nutr 1995;61: 1153-63

26. Ballot DE, MacPhail AP, Bothwell TH, et al. Fortification of curry powder with $\mathrm{NaFe}($ III)EDTA: report of a controlled iron fortifiction trial. Am J Clin Nutr 1989;49:162-9

27. JECFA. Joint FAO/WHO Expert Committee on Food Additives. Fifty-third meeting. Geneva: WHO, 1999

28. Bovell-Benjamin AC, Viteri FE, Allen LH. Iron absorption from ferrous bisglycinate and ferric trisglycinate in whole maize is regulated by iron status. Am J Clin Nutr 2000;71:1563-9

29. Fox TE, Eagles J, Fairweather-Tait SJ. Bioavailability of iron glycine as a fortificant in foods. Am J Clin Nutr 1998;67:664-8

30. Olivares M, Pizarro F, Pineda O, et al. Milk inhibits and ascorbic acid favors ferrous bis-glycine chelate bioavailability in humans. J Nutr 1997;127:1407-11

31. Monsen EL, Hallberg L, Layrisse M, et al. Estimation of available dietary iron. Am J Clin Nutr 1978;31: 134-41

32. Calvo E, Hertrampf E, de Pablo S, et al. Haemoglobin-fortified cereal: an alternative weaning food with high iron bioavailability. Eur J Clin Nutr 1989;43: 237-43

33. Davidsson L, Galan P, Cherouvrier F, et al. Iron bioavailability from infant cereals by infants: the effect of dephytinization. Am J Clin Nutr 1997;65: 916-20
34. Hertrampf E, Olivares M, Pizarro F, et al. Haemoglobin fortified cereal: a source of available iron in breast-fed infants. Eur J Clin Nutr 1990;44:793-8

35. Walter T, Hertrampf E, Pizarro F, et al. Effect of bovine-hemoglobin-fortified cookies on iron status of school children: a nationwide programme in Chile. Am J Clin Nutr 1993;57:190-4

36. Hurrell RF. Types of iron fortificants. Nonelemental sources. In: Clydesdale FM, Wiemer KL, eds. Iron fortification of foods. Orlando: Academic Press, 1985:39-53

37. Hurrell RF, Reddy MB, Burri J, Cook JD. An evaluation of EDTA compounds for iron fortification of cereal-based foods. Br J Nutr 2000;84:903-10

38. Davidsson L, Dimitriou T, Boy E, et al. Iron bioavailability from iron fortified Guatemalan meals based on corn masa tortillas and black bean paste. Am J Clin Nutr 2002;75:535-9

39. Sivakumar B, Brahmam GNV, Madhavan Nair K, et al. Prospects of fortifying salt with iron and iodine. Br J Nutr 2001;85:S167-73

40. Hallberg L. Bioavailability of dietary iron in man. Annu Rev Nutr 1981;1:123-47

41. Cook JD, Monsen ER. Vitamin C, the common cold, and iron absorption. Am J Clin Nutr 1977;30:235-41

42. Siegenberg D, Baynes RD, Bothwell $\mathrm{TH}$, et al. Ascorbic acid prevents the dose-dependent inhibitory effects of polyphenols and phytates on nonheme iron absorption. Am J Clin Nutr 1991;53: 537-41

43. Davidsson L, Walczyk T, Morris A, Hurrell RF. Influence of ascorbic acid on iron absorption from an iron-fortified, chocolate-flavored milk drink in Jamaican children. Am J Clin Nutr 1998;67:873-7

44. Disler PB, Lynch SR, Charlton RW, et al. Studies on the fortification of cane sugar with iron and ascorbic acid. Br J Nutr 1975;34:141-8

45. Derman DP, Bothwell TH, MacPhail AP, et al. Importance of ascorbic acid in the absorption of iron from infant foods. Scand J Haematol 1980;45:193201

46. Stekel A, Olivares M, Pizarro F, et al. Absorption of fortification iron in milk formulas by infants. Am J Clin Nutr 1986;43:917-22

47. Fairweather-Tait SJ, Wortley GM, Teusher B, Dainty J. Iron absorption from a breadfast cereal. Effects of EDTA compounds and ascorbic acid. Int $\mathrm{J}$ Vitam Nutr Res 2001;70:117-22

48. Davidsson L, Galan P, Kastenmayer P, et al. Iron absorption in infants: the influence of phytic acid and ascorbic acid in formulas based on soy isolate. Paediatr Res 1994;36:816-22

49. Davidsson L, Dimitriou T, Walczyk T, Hurrell R. Iron absorption from experimental infant formulas based on pea (Pisum sativum)-protein isolate: the effect of phytic acid and ascorbic acid. Br J Nutr 2001;85: 59-63

50. Davidsson L, Walczyk T, Zavaleta N, Hurrell RF. Improving iron absorption from a Peruvian school breakfast meal by adding ascorbic acid or Na2EDTA1-3. Am J Clin Nutr 2001;73:83-87

51. El-Guindi M, Lynch SR, Cook JD. Iron fortification from fortified flat breads. Br J Nutr 1988;59:205-13

52. MacPhail AP, Patel RC, Bothwell TH, Lamparelli RD. 
EDTA and the absorption of iron from food. Am J Clin Nutr 1994:59:644-8

53. Hurrell RF, Juillerat MA, Reddy MB, et al. Soy protein, phytate and iron absorption in man. Am J Clin Nutr 1992;56:573-8

54. Hallberg L, Brune M, Rossander L. Iron absorption in man: ascorbic acid and dose-dependent inhibition by phytate. Am J Clin Nutr 1989;49:140-4

55. Hurrell RF. Enhanced iron absorption from cereal and legume grains by phytic acid degradation. In: Lee TC, Ho TC, editors. Effects of food processing on bioactive compounds in foods. American Chemical Society Symposium Series No. 816, Cary, NC: Oxford University Press, 2002

56. Hotz C, Gibson RS, Temple L. A home-based method to reduce phytate content and increase zinc bioavailability in maize-based complementary diets. Int J Food Sci Nutr 2001;52:133-42

57. Bishnoi S, Khetarpaul N, Yadav RK. Effects of domestic processing and cooking methods on phytic acid and polyphenol contents of pea cultivars (Pisum sativum). Plant Foods Hum Nutr 1994; 45:381-8
58. Marero LM, Payumo EM, Aguinaldo AR, et al. The antinutritional factors in weaning foods prepared from germinated legumes and cereals. Lebensmittelwissenschaft und Technologie 1991;24:177-81

59. Sharma A, Kapoor AC. Levels of antinutritional factors in pearl millet as affected by processing treatment and various types of fermentation. Plant Foods Hum Nutr 1996;49:241-52

60. Egli I. Traditional food processing methods to increase mineral bioavailability from cereal and legume based weaning foods. Diss. ETH No. 13980, 2001

61. Barclay D, Davidsson L, Egli I, et al. Cereal products having low phytic acid content. International Patent, publication no WO/00/72700, 2000

62. Elwood PC, Waters WE, Sweetran P. The haematinic effect of iron in flour. Clin Sci 1971;40:31-7

63. Staubli Asobayire F, Adou P, Davidsson L, et al. Prevalence of iron deficiency, with and without concurrent anemia, in population groups with high prevalence of malaria and other infections. A study in Côte d'Ivoire. Am J Clin Nutr 2001;74:776-82 